\title{
Capillary electrophoresis for the characterization of quantum dots after non-selective or selective bioconjugation with antibodies for immunoassay
}

\author{
Mark Pereira and Edward PC Lai*
}

Address: Department of Chemistry, Ottawa-Carleton Chemistry Institute, Carleton University, Ottawa, ON K1S 5B6, Canada

Email: Mark Pereira - mpereir2@connect.carleton.ca; Edward PC Lai* - edward_lai@carleton.ca

* Corresponding author

Published: I October 2008

Journal of Nanobiotechnology 2008, 6:10 doi:10.1186/1477-3155-6-10

This article is available from: http://www.jnanobiotechnology.com/content/6/1/10

(c) 2008 Pereira and Lai; licensee BioMed Central Ltd.

This is an Open Access article distributed under the terms of the Creative Commons Attribution License (http://creativecommons.org/licenses/by/2.0), which permits unrestricted use, distribution, and reproduction in any medium, provided the original work is properly cited.
Received: 3 May 2008

Accepted: I October 2008

\footnotetext{
which permits unrestricted use, distribution, and reproduction in any medium, provided the original work is properly cited.
}

\begin{abstract}
Capillary electrophoresis coupled with laser-induced fluorescence was used for the characterization of quantum dots and their conjugates to biological molecules. The CE-LIF was laboratory-built and capable of injection (hydrodynamic and electrokinetic) from sample volumes as low as $4 \mu \mathrm{L}$ via the use of a modified micro-fluidic chip platform. Commercially available quantum dots were bioconjugated to proteins and immunoglobulins through the use of established techniques (non-selective and selective). Non-selective techniques involved the use of EDCHCl/ sulfo-NHS for the conjugation of BSA and myoglobin to carboxylic acid-functionalized quantum dots. Selective techniques involved I) the use of heterobifunctional crosslinker, sulfo-SMCC, for the conjugation of partially reduced IgG to amine-functionalized quantum dots, and 2) the conjugation of periodate-oxidized $\mathrm{lg}$ Gs to hydrazide-functionalized quantum dots. The migration times of these conjugates were determined in comparison to their non-conjugated QD relatives based upon their charge-to-size ratio values. The performance of capillary electrophoresis in characterizing immunoconjugates of quantum dot-labeled lgGs was also evaluated. Together, both QDs and CE-LIF can be applied as a sensitive technique for the detection of biological molecules. This work will contribute to the advancements in applying nanotechnology for molecular diagnosis in medical field.
\end{abstract}

\section{Background}

Quantum dots (QDs) are fluorescent nanoparticles that receive increasing recognition as a viable alternative (to conventional organic fluorophores) for molecular labeling. Their quantum mechanical and electronic characteristics give QDs unique optical properties that are advantageous in the fields of bioanalytical, biomedical and biophotonic research. Such optical properties include size-tunable emission wavelengths, broad excitation wavelengths, long fluorescence lifetimes, large Stokes shifts, and high quantum yields [1-3]. Other advantageous properties include resistance to photo- and chemical- degradation and their capability for performing multiplexing experiments [3]. QDs are relatively large particles, with typical diameters ranging from 1-10 nm [1]. The inorganic core (typically a semiconductor) is responsible for their fluorescent properties. This core is typically surrounded by a shell ( $\mathrm{ZnS}$ is common) for protection from chemical- and photo-oxidation [2]. The shell also provides a means of functionalizing the QD with carbox- 
ylic acids or primary amines, for good solubility in aqueous solutions and relative ease of specific labeling reactions [1].

QDs, often applied for the labeling of biological molecules (proteins, peptides, antibodies, etc.), require specific techniques for their conjugation [4-7]. The most popular bioconjugation technique involves the use of a zerolength crosslinker, 1-ethyl-3- [3-dimethylaminopropyl]carbodiimide hydrochloride (EDCHCl) [1-4,6,7], in the presence of a hydrophilic active group, N-hydroxysulfosuccinimide (sulfo-NHS) [8], for the formation of a stable amide bond between carboxylic acid-functionalized QDs (QD-COOH) and any biomolecules containing a primary amine [9] (Figure 1).

This method, while proven to yield exclusively QD-protein conjugates in a controlled manner, randomizes the location on a protein to which conjugation can occur, resulting in a non-selective bioconjugation [9]. Despite high bioconjugation efficiencies, this can be detrimental in the case where an immunoassay is to be performed next. For instance, a labeled protein serving as an antigen might lose its antigenicity (ability to bind an antibody) when conjugated to a large QD. A similar concern can be conveyed if an antibody were conjugated in a region close to the antigen-binding site (the hypervariable region). Either one of these variations can significantly reduce the efficiency of immunoassay applications [9].

Other techniques make effective use of selective bioconjugation, targeting specific sites on the protein. These include the use of a heterobifunctional crosslinker such as sulfosuccinimidyl-4-(N-maleimidomethyl)cyclohexane1-carboxylate (sulfo-SMCC) [9-11]. In the case for antibodies, as shown in Figure 2 below, sulfo-SMCC can form stable amide bonds to amine-functionalized QDs (QD$\mathrm{NH}_{2}$ ) [9]. The resultant QDs, through sulfo-SMCC's maleimide region, can next form stable a thioether bond with a sulfhydryl-exposed antibody [9]. Mild reducing reagents such as cysteamineHCl (or DTT) can selectively cleave the disulfide bonds (hinge region) connecting the IgG heavy chains, while leaving the other disulfide bonds that make up the antigen binding site (hypervariable region) unaffected, thus producing a partially reduced IgG (rIgG) [12]. In addition, the resulting exposed sulfhydryls (hinge region) are sufficiently far away (from the hypervariable region) for QD-bioconjugation to occur. The resulting
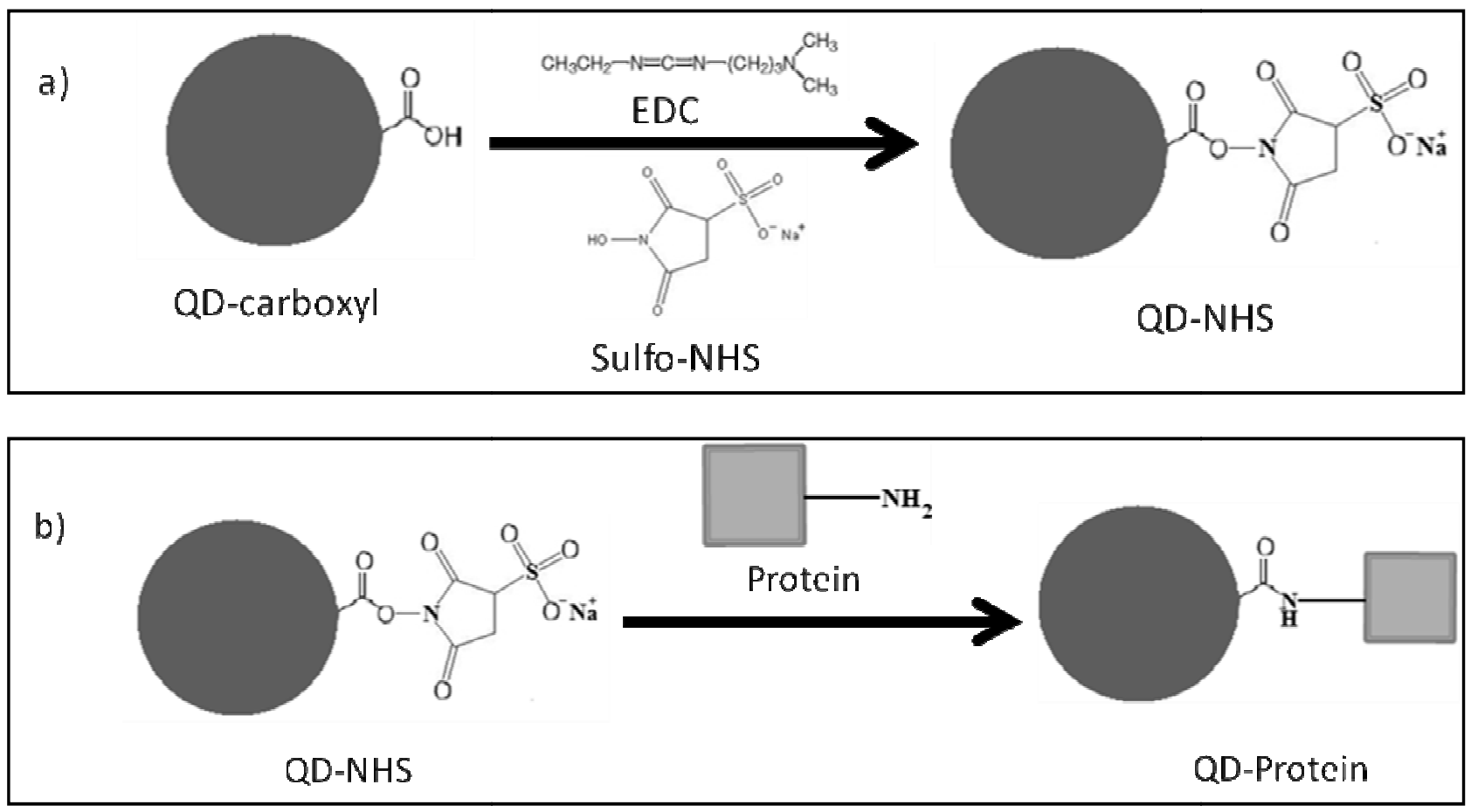

Figure I

Non-selective bioconjugation reaction scheme of carboxylated QDs (QD-COOH) to amine-containing proteins. This two-step reaction involves a) the activation of QD-COOH with EDC/sulfo-NHS, resulting in a semi-stable active ester (QD-NHS), and b) the nucleophilic reaction between the QD-NHS and amine-containing protein, forming a QD-protein conjugate via a stable amide bond. 

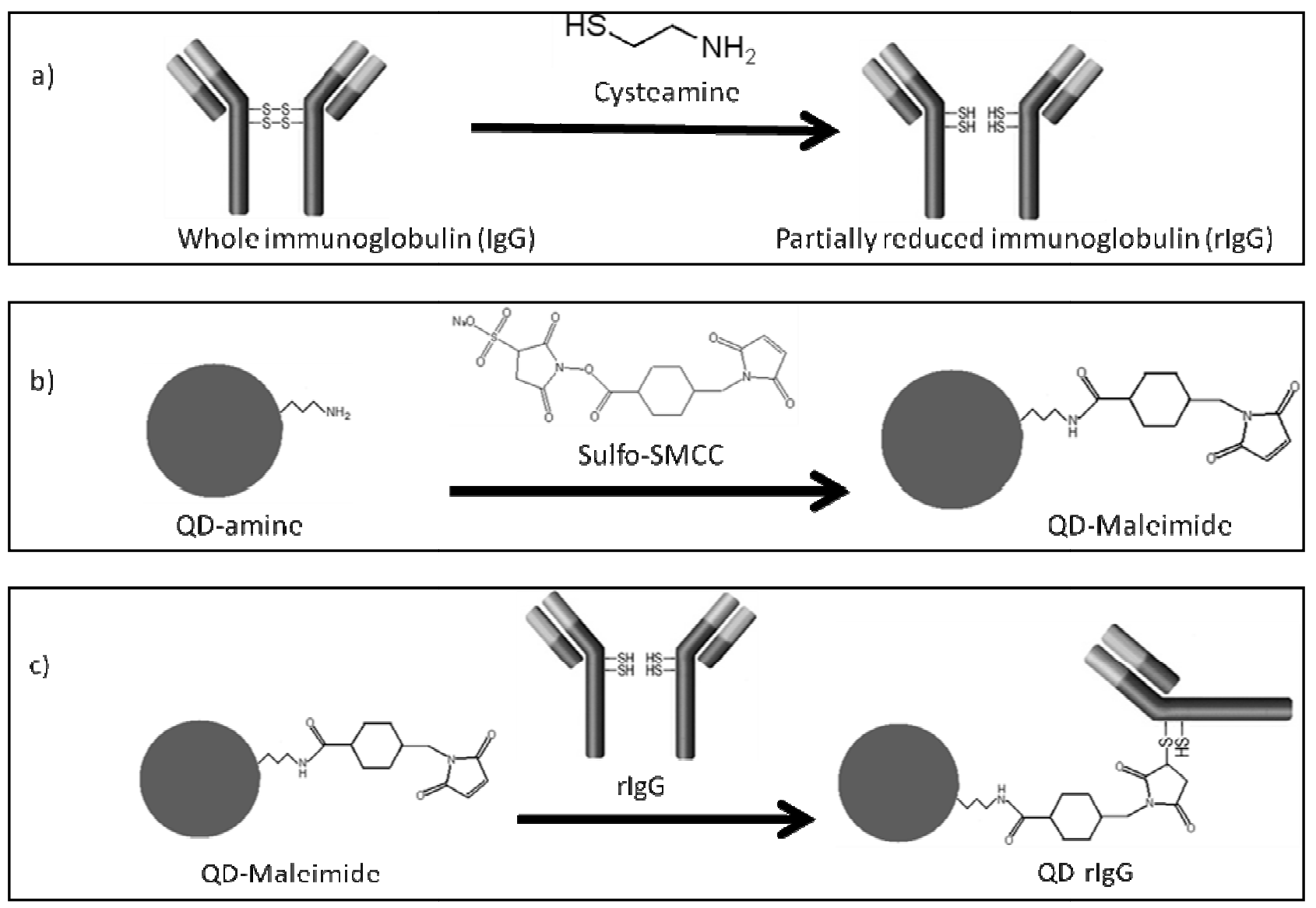

\section{Figure 2}

Selective bioconjugation reaction scheme of amino QDs (QD-amine) to free sulhydryl-containing IgG antibodies. The reaction involves a) the mild reduction of IgG with cysteamine to yield partially reduced lgG antibody fragments ( $\mathrm{rlgG})$; b) the activation of QD- $\mathrm{NH}_{2}$ by nucleophilic reaction with NHS-moiety of sulfo-SMCC, resulting in maleimide-functionalized quantum dot (QD-maleimide); and c) the rlgG and QD-maleimide conjugation (QD-rlgG) via the formation of a thioether bond.

quantum dot-conjugated half antibody (QD-rIgG) will allow an immunoreaction to proceed readily.

Reductive amination is a bioconjugation technique popular in the labeling of glycoproteins. Taking advantage of the polysaccharide chains within the Fc region of an antibody, it can allow bioconjugation to occur relatively far away from the antigen binding site. Through oxidation (using sodium periodate) of the carbohydrate hydroxyls, the aldehydes formed are highly reactive toward primary amines and hydrazides [9]. This makes QD-NH $\mathrm{NH}_{2}$ or QD$\mathrm{COOH}$ (derivatized with adipic acid dihydrazide $(\mathrm{ADH})$ ) suitable candidates for conjugation [9]. In addition, selective bioconjugation can occur without a proceeding reduction reaction, thus retaining the integrity of the antibody (Figure 3).
Capillary electrophoresis (CE) has seen increasing use in the separation and characterization of inorganic nanoparticles ( $\mathrm{Ag}, \mathrm{Au}, \mathrm{TiO}_{2}, \mathrm{Al}_{2} \mathrm{O}_{3}, \mathrm{Fe}_{2} \mathrm{O}_{3}$ ) [13-17], polystyrene microspheres [18], biomolecules (proteins, peptides) [1930], QDs [31], QD-conjugates with bovine serum albumin (BSA) and horse radish peroxidase (HRP) [7], and QD-conjugates with Ulex europaeus (UEA-1) and anti-von Willebrand factor (anti-vWF) [32]. CE has also been used for immunoassays involving hepatitis $\mathrm{B}$, prion protein, alpha-fetoprotein, etc [24-30]. Recently, a CE-based immunoassay involving QDs conjugated to anti-IgM antibodies followed by immuno-conjugation to its complimentary antigen IgG was performed with satisfactory results [33]. Another recent advancement involved the CE-characterization of QDs (of differing emission wavelengths) exclusively conjugated to biotin and streptavidin 

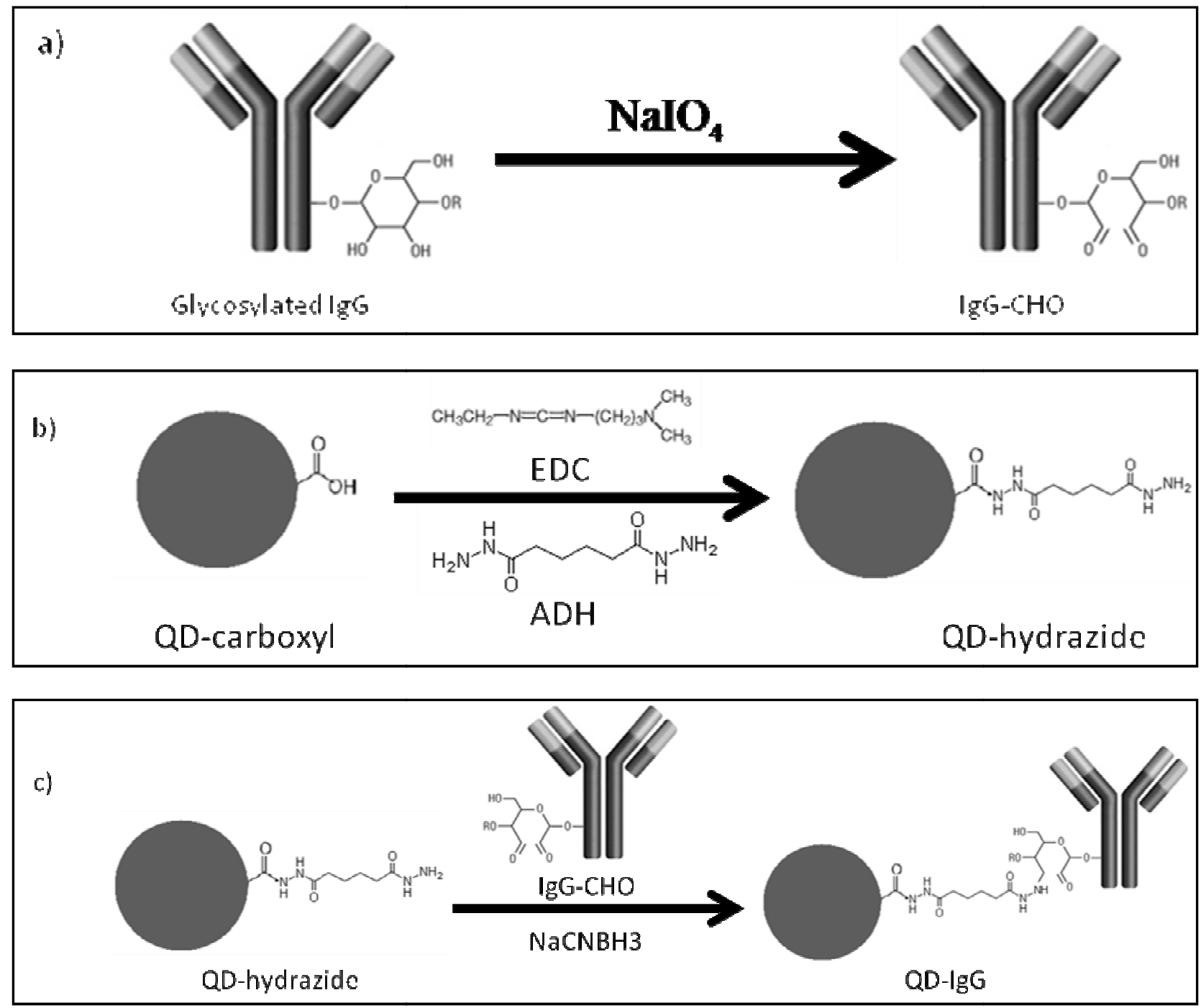

Figure 3

Selective bioconjugation reaction scheme of hydrazide QDs (QD-hydrazide) to aldehyde-containing IgG antibodies (IgG-CHO). The reaction involves a) mild periodate oxidation of glycosylated IgG, yielding lgG-CHO; b) synthesis of QD-hydrazide via derivatization of QD-COOH with EDC/ADH; and c) conjugation of QD-hydrazide with IgG-CHO via formation of hydrazone linkage to yield QD-lgG.

[34]. Their work followed the characterization of the conjugates' affinity to each other via strong biotin-streptavidin interactions. However, present publications reporting the use of QDs in CE-based immunoassays are very preliminary, due in part to a QD-biomolecule conjugate's (and immunoconjuagte's) complex charge-to-size ratio. Thus, more research is required in its development as a fast and efficient method for performing immunoassays.

In this paper, we report more preliminary results of covalently bioconjugating QDs to various biomolecules (pro- teins and immunoglobulins). These QD-conjugated biomolecules are characterized via a laboratory-built capillary electrophoresis instrument with laser-induced fluorescence detection (CE-LIF) [35]. The instrumental capabilities (comparable to commercial CE-LIF systems) include the use of a micro-sample injection platform that can load sample volumes as low as $4 \mu \mathrm{L}$ [35]. We also discuss some of the challenges faced when performing bioconjugation through the various schemes described above. The purpose is to validate a fast, selective, and reproducible CE-LIF analysis method that can be efficient 
and robust. This work will evolve to perform QD-based immunoassays using CE-LIF as an effective separation and sensitive detection technique. The aim is to apply this research in the area of infectious biological materials that are generally present in relatively low concentrations and small volumes.

\section{Methods \\ Chemicals and reagents}

Boric acid (certified A.C.S.), sodium meta-periodate (crystalline, A.C.S. grade), sodium hydroxide (reagent grade) were purchased from Fisher Scientific (Ottawa, Ontario, Canada). CdSe/ZnS carboxy-terminated QDs (Maple RedOrange, $620 \mathrm{~nm}$ ) and CdSe/ZnS amine-terminated QDs (Maple Red-Orange, $620 \mathrm{~nm}$ ) were purchased from Evident Technologies (Troy, NY, USA). EDCHCl, Sulfo-NHS, lysozyme (Lys), and MES buffered saline packs were purchased from Pierce Biotechnology. Sodium acetate (reagent grade) and hydroxylamine hydrochloride (reagent grade) was purchased from Anachemia. EDTA (0.1 M volumetric standard), $\mathrm{ADH}(=98 \%)$, sulfo-SMCC (=98\%), DL-DTT (1 $\mathrm{M}$ in water solution), anti-human albumin (polyclonal IgG produced in rabbit), human serum albumin (HSA), cysteamine hydrochloride (Purum = 97.0\%), 2-mercaptoethanol (14 M), 10× PBS concentrate, bovine serum albumin (BSA), horse myoglobin (Myo) cytochrome c (CytC), ethanolamine, and sodium cyanoborohydride ( $5 \mathrm{M}$ in $1 \mathrm{M}$ sodium hydroxide) were purchased from Sigma Aldrich. Coumarin 521 was purchased from Exciton (Dayton, Ohio, USA). Micro-centrifuge tubes (50 $\mathrm{kDa}$ and $100 \mathrm{kDa}$ MWCO) were purchased from Fisher Scientific.

\section{Preparation of buffer solutions and stock solutions}

All buffer solutions were prepared and $\mathrm{pH}$-adjusted using sodium hydroxide (10 M, $5 \mathrm{M}$, and $1 \mathrm{M}$ ) and hydrochloric acid ( $1 \mathrm{M}$ and $0.5 \mathrm{M}$ ). All CE separation buffers were filtered through a $0.45 \mu \mathrm{m}$ membrane filter (Pall Corporation, Ann Arbor, MI, USA).

Carboxy- and amine- terminated QDs were used from supply stock $(11 \mu \mathrm{M})$ without any prior treatment.

Stock solutions of EDCHCl (20 mM) and sulfo-NHS (50 $\mathrm{mM}$ ) were prepared by dissolution of dry reagents in 0.1 M MES (pH 5.2) buffered saline and used immediately after preparation. Stock solutions of 2-mercaptoethanol ( $1 \mathrm{M}$ ) and hydroxylamine hydrochloride (1 M) were prepared and stored at room temperature.

Stock solutions of cysteamineHCl $(100 \mathrm{mM})$ were prepared by dissolution of dry reagent in $1 \times$ PBS (pH 7.2), 10 mM EDTA and used immediately after preparation. Stock solutions of DTT (100 mM) were prepared by dilution of a 1 M DTT stock solution and used within 3 days of preparation.

Stock solutions of $\mathrm{NaIO}_{4}(100 \mathrm{mM})$ were prepared by dissolution of dry reagents in $0.1 \mathrm{M}$ sodium acetate ( $\mathrm{pH} 5.5$ ) buffered saline. Preparation and storage was performed in minimal lighting and used immediately after use. Sodium cyanoborohydride ( $5 \mathrm{M}$ in $1 \mathrm{~N} \mathrm{NaOH}$ ) was used as prepared from supplier. Stock solution of ethanolamine (1 $\mathrm{M})$ was prepared by dissolution of dry reagent in distilled deionized water (ddw) and $\mathrm{pH}$ adjusted to 9.6.

Stock solutions $(1 \mathrm{mg} / \mathrm{mL})$ of bovine serum albumin (BSA), myoglobin (Myo), cytochrome c (CytC), and lysozyme (Lys), were prepared in $1 \times$ PBS (pH 7.2). Human serum albumin (HSA) was prepared in ddw $(11 \mathrm{mg} / \mathrm{mL})$. Anti-human albumin IgG $(4 \mathrm{mg} / \mathrm{mL})$ was prepared in $1 \times$ PBS (pH 7.2).

\section{Non-specific bioconjugation of whole IgG using EDCHCII sulfo-NHS}

A mixture containing $2 \mathrm{mM}$ EDCHCl, $5 \mathrm{mM}$ sulfo-NHS, and $1.1 \mu \mathrm{M}$ carboxy-terminated QDs (QD-carboxyl) was prepared in 0.1 M MES, pH 6.0 and incubated for $15 \mathrm{~min}$ utes at room temperature. The remaining unreacted EDC was quenched with the addition of 2-mercaptoethanol (1 M) to a final concentration of approximately $20 \mathrm{mM}$ and the mixture was left to stand for 10 minutes. The activated QDs were purified of unreacted reagents and byproducts by dialysis using $100 \mathrm{kDa}$ MWCO microcentrifuge tubes and re-suspended in $1 \times \mathrm{PBS}(\mathrm{pH} 7.2)$ containing dissolved protein. The reaction proceeded for 2 hours with gentle mixing. The reaction was quenched with addition of hydroxylamine hydrochloride $(1 \mathrm{M})$ to a final concentration of approximately $10 \mathrm{mM}$. The bioconjugation mixture was left to stand for 10 minutes at room temperature prior to purification by dialysis using $100 \mathrm{kDa}$ MWCO microcentrifuge tubes. The mixture was analyzed by CELIF and stored at $4^{\circ} \mathrm{C}$.

\section{Selective bioconjugation of reduced IgG (rlgG) using cysteamine $\mathrm{HCl}$ or DTT and sulfo-SMCC}

A mixture containing approximately $1 \mathrm{mg} / \mathrm{mL}$ rabbit antihuman albumin IgG and cysteamine $\mathrm{HCl}$ (concentration ranging from $0.1 \mathrm{mM}$ to $100 \mathrm{mM}$ ) was incubated at $37^{\circ} \mathrm{C}$ for 90 minutes in $0.1 \mathrm{M}$ sodium phosphate ( $\mathrm{pH} 7.0$ ), 0.15 $\mathrm{M}, 0.01 \mathrm{M}$ EDTA. The resulting partially reduced antibody (rIgG) was purified of byproducts and unreacted compounds via dialysis using a $50 \mathrm{kDa}$ MWCO microcentrifuge tube with successive washings of $0.1 \mathrm{M}$ sodium phosphate (pH 6.8), 0.15 M NaCl, 0.01 M EDTA buffer. The rIgG was temporarily stored at $4{ }^{\circ} \mathrm{C}$ until use for QD coupling. 
Amine-functionalized QDs (QD-amine) were added to a $50 \mathrm{mM}$ sodium phosphate ( $\mathrm{pH}$ 7.2) solution containing sulfo-SMCC $(8.8 \mathrm{mM})$ and incubated at room temperature for 60 minutes with gentle mixing. The maleimideactivated QDs (QD-maleimide) were purified of unreacted cross-linker via dialysis using $100 \mathrm{kDa}$ MWCO microcentrifuge tubes at room temperature with successive washings of $0.1 \mathrm{M}$ sodium phosphate ( $\mathrm{pH} 6.8$ ), 0.15 $\mathrm{M} \mathrm{NaCl}, 0.01 \mathrm{M}$ EDTA buffer. The purified QD-maleimide was used immediately.

The rIgG and QD-maleimide were combined and incubated overnight at $4^{\circ} \mathrm{C}$. Purification of QD-rIgG of "free" rIgG in solution was performed via dialysis using $100 \mathrm{kDa}$ MWCO microcentrifuge tubes. The purified QD-rIgG was washed several times with ddw. The purified QD-rIgG was analyzed by CE-LIF and stored at $4{ }^{\circ} \mathrm{C}$.

\section{Selective bioconjugation of whole IgG using EDCIADH and sodium meta-periodate}

A mixture containing $20 \mu \mathrm{L}$ QD-carboxyl $(11 \mu \mathrm{M}), 16 \mathrm{mg}$ EDCHCl, and $32 \mathrm{mg}$ ADH were incubated in $1 \mathrm{~mL} 1 \times$ PBS for 4 hours at room temperature with gentle mixing. The hydrazide-functionalized QDs (QD-hydrazide) were purified from excess reagents via dialysis using a $100 \mathrm{kDa}$ MWCO microcentrifuge tube. The purified concentrate was stored at $4^{\circ} \mathrm{C}$ until analysis by CE-LIF and IgG-CHO coupling.

A $500 \mu \mathrm{L}$ mixture containing approximately $1 \mathrm{mg} / \mathrm{mL}$ rabbit anti-human albumin IgG and sodium meta periodate dissolved in $0.1 \mathrm{M}$ sodium acetate buffered saline was incubated in the absence of light for 1 hour at room temperature with gentle mixing. The oxidized IgG (IgG-CHO) was purified of excess reagents via dialysis using a $100 \mathrm{kDa}$ MWCO. The purified IgG-CHO was used immediately.

The IgG-CHO was combined with QD-hydrazide $(50 \mu \mathrm{L}$ total volume) and incubated overnight (14 hrs) at room temperature with gentle mixing. Stabilization of the hydrazone linkages were performed via the addition of 5 $\mu \mathrm{L}$ sodium cyanoborohydride (5 $\mathrm{M}$ in $1 \mathrm{~N} \mathrm{NaOH})$ with continued incubation for 1 hour. Unreacted aldehydes were blocked via addition of $25 \mu \mathrm{L}$ of $1 \mathrm{M}$ ethanolamine ( $\mathrm{pH}$ 9.6) with continued incubation for 1 hour. Mixture was removed of excess sodium cyanoborohydride and ethanolamine via dialysis using $100 \mathrm{kDa}$ MWCO. Mixture was not purified of unreacted IgG or QD.

\section{Immunoconjugation of QD-rlgG with corresponding antigen}

A $10 \mu \mathrm{L}$ aliquot of immunogen HSA $(11 \mathrm{mg} / \mathrm{mL})$ was added to a $300 \mu \mathrm{L}$ solution of QD-rIgG (rabbit antihuman albumin) and incubated for 15 minutes at room temperature. The mixture was immediately analyzed be CE-LIF and later stored at $4^{\circ} \mathrm{C}$.

\section{CE-LIF analysis}

CE-LIF analysis of QDs, bioconjugates, and immunoconjugates were performed on a laboratory-built system described previously. A fused silica capillary $(51 \mathrm{~mm}$ id, $362 \mathrm{~mm}$ o.d., $L_{\mathrm{t}}=58.5 \mathrm{~cm}, L_{\mathrm{d}}=52.1 \mathrm{~cm}$, and $L_{\mathrm{dw}}=2 \mathrm{~mm}$ ) was flushed with $1.0 \mathrm{M} \mathrm{NaOH}, 0.1 \mathrm{M} \mathrm{NaOH}, \mathrm{DDW}$, and run buffer. Prior to each use, the capillary was equilibrated with the run buffer at an applied voltage of $25 \mathrm{kV}$ for 10 min. Capillary temperature was maintained constant at $20.0^{\circ} \mathrm{C}$ by water from a PolyScience $1160 \mathrm{~A}$ circulating bath (Niles, IL, USA). Hydrodynamic injections were performed by elevating the sample to $8 \mathrm{~cm}$ for $15 \mathrm{~s}$. Microsample injections were performed using the sample port of a modified microfluidic chip as described previously [34]. An Extreme DPSS 473 nm, 500 mW solid-state diode laser (Seabrook, TX, USA) was used for fluorescence excitation. The LIF intensity was detected using a Hamamatsu model H7827-001 PMT (Bridgewater, NJ, USA) equipped with a $620 \pm 5 \mathrm{~nm}$ interference filter. Spectral response of the PMT was 300-650 nm. The detector output signal was acquired through the Peak Simple Chromatography Data System.

\section{Results and discussion Use of EDCHCI/sulfo-NHS as a non-selective technique for bioconjugation of QDs to proteins}

This non-selective technique for bioconjugation involved a two-step reaction using $\mathrm{EDCHCl} /$ sulfo-NHS to control the conjugate formation. Bioconjugation of proteins to carboxylated QDs have been performed with the use of EDC alone [7]. Despite the simplicity of a one-step reaction, the drawback involves a degree of uncontrollability during bioconjugation, forming unlabeled protein-protein conjugates and QD-protein polymers that can ultimately lead to precipitation. The use of sulfo-NHS was included to prevent these unwanted conjugate by-products and yield exclusively QD-protein conjugates. However, the number of proteins bound to a single QD may vary (depending on experimental conditions) and have yet to be determined.

Figure 4 illustrates the CE separation of carboxylated QDs (QD-COOH) (1) from their conjugation to BSA (QDBSA) (2). The QD-BSA was detected at a longer migration time with respect to $\mathrm{QD}-\mathrm{COOH}$ due to the inherent increase in the net negative charge of the conjugate. This was expected since the isoelectric point (pI) of BSA ( $\sim 5.6)$ is much lower than the CE buffer $\mathrm{pH}$ (9.2) and thus expressing an increased number of negative charges that will ultimately influence the net-charge of the conjugate. The increase in peak width of the QD-BSA can be attributed to a number of factors, including the polydispersity 


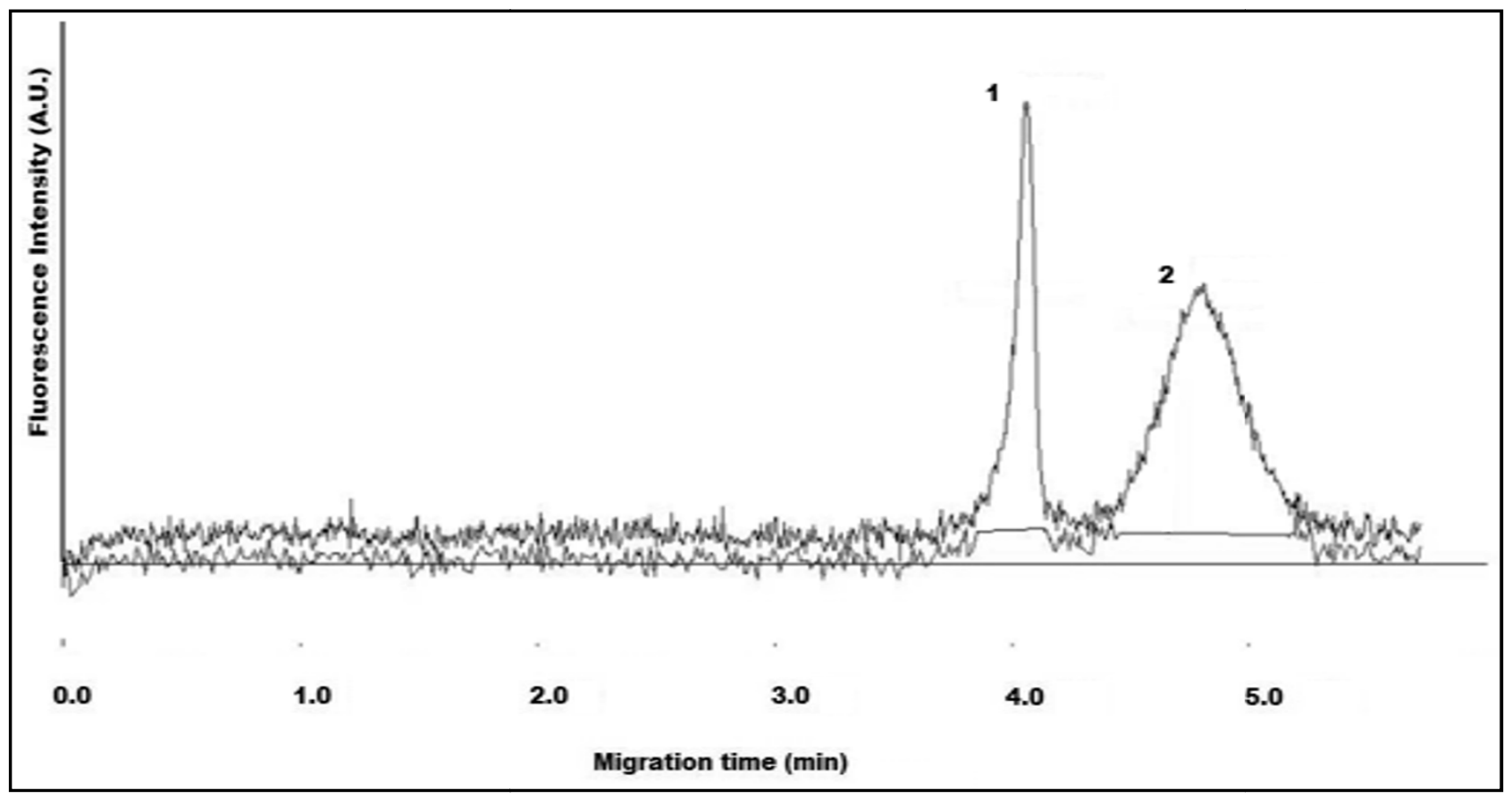

\section{Figure 4}

Electropherogram of mixture containing QD-COOH (I) and BSA-conjugated QDs (QD-BSA) (2). CE buffer electrolyte used was $50 \mathrm{mM}$ borate, $\mathrm{pH}$ 9.2. Gravity injection performed by elevating inlet capillary $7 \mathrm{~cm}$ for $5 \mathrm{~s}$. Applied voltage for CE separation was $20 \mathrm{kV}$. Capillary temperature maintained at $20^{\circ} \mathrm{C}$. Excitation source and detection wavelength was $473 \mathrm{~nm}$ and $620 \mathrm{~nm}$, respectively.

of QDs during synthesis, the binding ratio of BSA to QDs, and the protein-capillary wall interactions that can take place with protein functionalized-QDs.

Figure 5 illustrates the CE separation of QD-COOH (1) with their conjugation to myoglobin (QD-Myo) (2). The migration time of QD-Myo is also longer with respect to QD-COOH. However the differences are not substantial enough for baseline separation to occur. In comparison to QD-BSA, there may be a weakened net negative charge that is present on QD-Myo, since myoglobin has a $\mathrm{pI}$ value measured at $\sim 7.2$. In addition, there is a considerable size difference between BSA (MW 66 kDa) and Myo (MW 16.7 kDa) that may likely influence the respective conjugate's migration time. As both MW and pI can influence a protein's charge-to-size ratio, their conjugation to polydisperse QDs (each with possibly different binding ratios) will contribute to their respective migration times.

The chemistry of bioconjugating QD-COOH to proteins using $\mathrm{EDCHCl} /$ sulfo-NHS was attractive due to its versatility, as primary amines (lysine $\varepsilon$-amine and $\mathrm{N}$-terminal $\alpha$-amine) are present on many proteins. This ultimately led to the attempt of bioconjugating QD-COOH to proteins of increasingly higher $\mathrm{pI}$, using cationic proteins such as cytochrome c and lysozyme. However, it was observed that the pI of proteins can play a determining factor in the efficiency of a bioconjugation. While the reaction was efficient in conjugating anionic proteins (BSA and myoglobin) to QD-COOH, it was unsuccessful in conjugating to cationic proteins (cytochrome c and lysozyme). It is suspected that the pI of cytochrome c ( 10) and lysozyme $(\sim 11)$ maintained the primary amines (those accessible for conjugation) in a protonated state. This protonated state would render these proteins poor in a nucleophilic reaction with the NHS-activated QD$\mathrm{COOH}$ (QD-NHS), thus inhibiting bioconjugation. The lack of a bioconjugation results in an eventual hydrolysis reaction with QD-NHS leading to the formation of the QD-COOH which can be identified using CE (data not shown).

Another drawback for the use of EDCHCl/sulfo-NHS for the formation of stable bioconjugates is the lack of specificity on the protein of interest. As numerous amine functional groups can be distributed throughout the surface of 


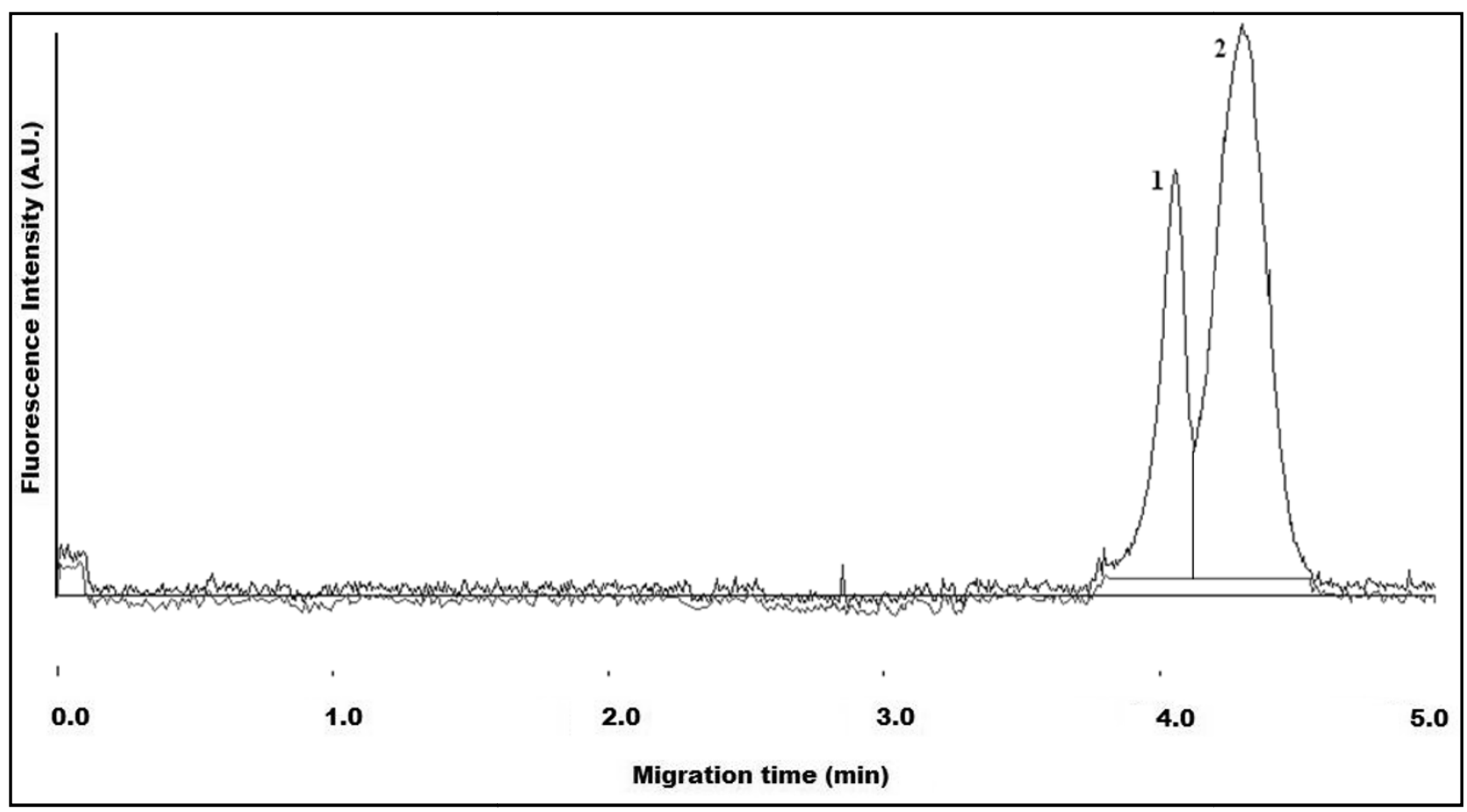

\section{Figure 5}

Electropherogram of mixture containing QD-COOH (I) and myoglobin-conjugated QDs (QD-Myo) (2). CE buffer electrolyte used was $50 \mathrm{mM}$ borate, $\mathrm{pH}$ 9.2. Gravity injection performed by elevating inlet capillary $7 \mathrm{~cm}$ for $5 \mathrm{~s}$. Applied voltage for CE separation was $20 \mathrm{kV}$. Capillary temperature maintained at $20^{\circ} \mathrm{C}$. Excitation source and detection wavelength was $473 \mathrm{~nm}$ and $620 \mathrm{~nm}$, respectively.

the protein, a bioconjugation involving such functional groups via a EDCHCl/sulfo-NHS reaction would lead to a randomization of crosslinking sites.

Use of selective (heterobifunctional crosslinker) technique for bioconjugation of QDs to IgGs

The use of the heterobifunctional crosslinker sulfo-SMCC allowed for straightforward activation of amine-function- alized QDs (QD-NH$)$ via a nucleophilic reaction between the active ester on the crosslinker and the amine moiety of the QD. Despite the activated QD (QD-maleimide) being relatively stable at physiological $\mathrm{pH}$, temperature is an important factor to control as higher temperatures (above room temperature) can accelerate hydrolysis reactions. Hydrolysis of the maleimide moiety will form maleamic acid that is unreactive towards free

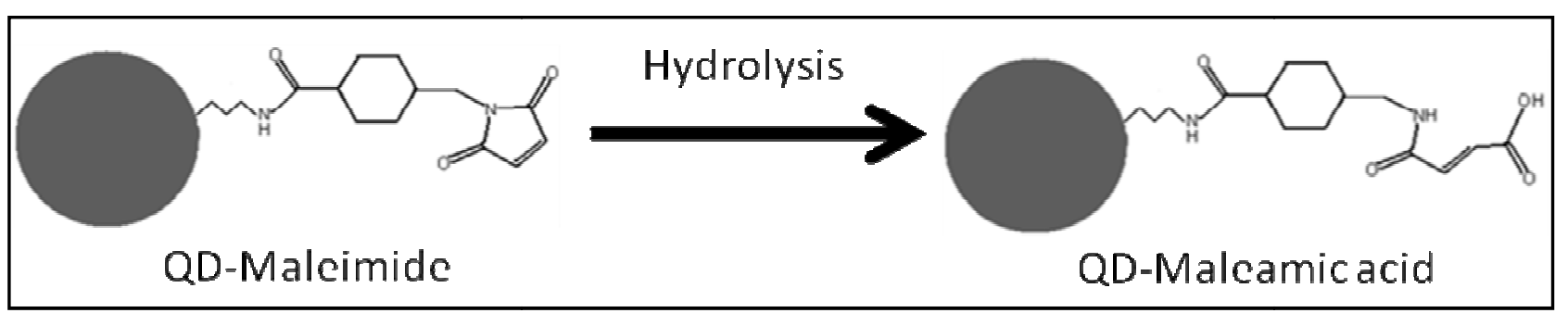

\section{Figure 6}

Reaction scheme illustrating hydrolysis of sulfo-SMCC activated of QD-NH $\mathbf{N}_{2}$ (QD-maleimide). Hydrolyzed QDmaleimide will contain maleamic acid moiety (QD-maleamic) unreactive towards free sulfhydryls. 
sulfhydryls (Figure 6). Characterization of the hydrolyzed QD-maleimide by CE detected a migration time similar to that for QD-COOH (data not shown).

Due to the high-pH instability of QD-maleimide, CE characterization was not performed. However, it can be expected that the neutral charge present on the maleimide would compel the QD-maleimide to migrate more slowly, relative to the positively charged $\mathrm{QD}$-amine prior to activation. The use of either cysteamine $\mathrm{HCl}(50-100 \mathrm{mM})$ or DTT (1-10 mM) as the reducing agent for IgGs provided similar results. However, both incubation time and temperature are dramatically different $\left(90 \mathrm{~min}\right.$ at $37^{\circ} \mathrm{C}$ for cysteamine $\mathrm{HCl}$ and $30 \mathrm{~min}$ at room temperature for DTT). Furthermore, the use of $50 \mathrm{kDa}$ MWCO centrifuge filters allowed for retention of the partially-reduced IgG (rIgG), while removing unused reagents and byproducts. Combining of the QD-maleimide with rIgG at room temperature for at least 2 hours (or at $4{ }^{\circ} \mathrm{C}$ overnight) provided similar results shown in Figure 7 below.

Figure 7 illustrates overlapping electropherograms of QD$\mathrm{NH}_{2}$ (1) and their conjugation to the reduced anti-human albumin IgG (QD-rIgG) (2). The longer migration time observed for QD-rIgG can lead to the assumption that the rIgG exhibits a net negative charge in this CE separation buffer. Thus, when conjugated to the positively charged QD- $\mathrm{NH}_{2}$, the charge influence of the rIgG results in the conjugate displaying a smaller net positive charge. It is suspected that the IgG is comparable in acidity to the smaller proteins (BSA and myoglobin) used, however other factors including size and QD:biomolecule binding ratios need to be taken into consideration. Similar electropherograms were obtained when conjugating QD-NH $\mathrm{N}_{2}$ to another IgG, anti-chicken lysozyme (data not shown). This can be attributed to IgGs having MWs typically at 150 $\mathrm{kDa}$. However, IgG can range in pI from 6.4 to 9.0, due mainly to changes in their hypervariable region which can contain various charged residues. Thus, changes in CE separation buffer (particularly $\mathrm{pH}$ ) could possibly influence the relative migration times of QDs conjugated to different IgGs and hence aid in selectivity and resolution. The observed migration time for the EOF was measured slightly earlier than the QD-NH $\mathrm{N}_{2}$ (data not shown). This was unexpected since these observations would suggest QD- $\mathrm{NH}_{2}$ expressing a net negative charge. However, higher concentration borate buffers (greater than 200 $\mathrm{mM}$ ) did measure the EOF at a later migration time than

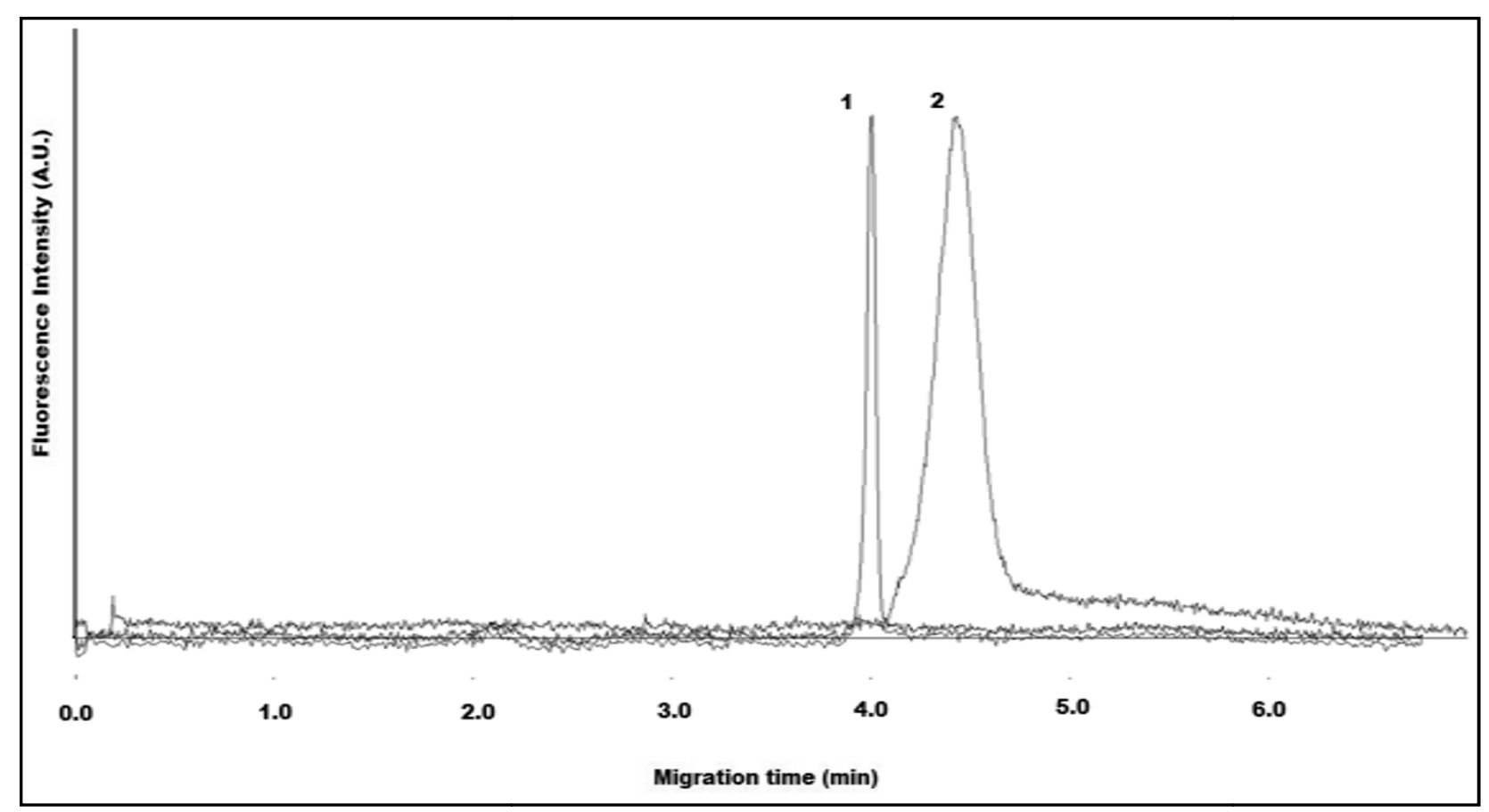

\section{Figure 7}

Overlapping electropherograms illustrating QD- $\mathrm{NH}_{2}(\mathrm{I})$ and QDs conjugated to reduced antibodies QD-rIgG (2). IgG used for conjugation was rabbit anti-human albumin. CE buffer electrolyte used was $50 \mathrm{mM}$ borate, $\mathrm{pH} 9.2$. Gravity injection performed by elevating inlet capillary $7 \mathrm{~cm}$ for $5 \mathrm{~s}$. Applied voltage for CE separation was $25 \mathrm{kV}$. Capillary temperature maintained at $20^{\circ} \mathrm{C}$. Excitation source and detection wavelength was $473 \mathrm{~nm}$ and $620 \mathrm{~nm}$, respectively 
QD-NH $\mathrm{N}_{2}$ (data not shown). The reason for the unexpected migration time for QD- $\mathrm{NH}_{2}$ at different borate concentrations may require further knowledge of the commercialized QD coating/functionalization process.

\section{Use of selective (hydrazone linkage) technique for conjugation of IgGs to QDs}

Conjugation of IgG-CHO with QD- $\mathrm{NH}_{2}$ is possible using reductive amination. However, the drawback is the degree of uncontrollability of the resulting conjugate, as undesirable IgG-IgG crosslinking can occur through the presence of primary amines on the IgGs surface. Thus, conjugating IgG-CHO with QDs functionalized with hydrazides was reasoned to be more selective as conjugation is occurring exclusively on the polysaccharide chain. However, since commercially obtainable QDs are typically functionalized with carboxylic acids or amines, a derivatization was required. Derivatization was performed on QD-COOH and involved the use of EDCHCl in the presence of the bis-hydrazide compound, $\mathrm{ADH}$, yielding relatively stable hydrazide-functionalized QDs (QD-hydrazide). The drawback is that $\mathrm{ADH}$, being is homobifunctional crosslinker, can introduce undesirable side reactions. As both functional groups on the crosslinker are identical, they each have the potential of reacting with the same QD, resulting in a closed ring structure that can essentially inactivate that particular region of the QD. However, it is suspected that the spacer arm of the crosslinker lacks the length required to form such a ring structure. Another more likely scenario involves the cross-reaction between a derivatized QD (QD-hydrazide) with an underivatized QD (QD-COOH). This uncontrolled reaction can lead to the undesirable formation of a QD-QD polymer (Figure $8 \mathrm{a}$ ), but is believed to be minimized when using $\mathrm{ADH}$ in excessive quantities during the derivatization.

Figure 9 illustrates overlapping electropherograms of QDhydrazide (2) in comparison to QD- $\mathrm{NH}_{2}$ (1) and QD$\mathrm{COOH}$ (3). Their characteristic migration times can be attributed to the $\mathrm{pKa}$ of the functional group expressed on the QD relative to the $\mathrm{pH}$ of the CE separation buffer (9.2). Alkylated primary amines and carboxylic acids have measured pKa $\sim 10$, and $\sim 4.5$, respectively. Thus, the effect of the CE separation buffer $\mathrm{pH}$ allows the QD-NH $\mathrm{N}_{2}$ to exhibit a net positive charge due to protonation of the primary amines. However, the QD-COOH will be com-
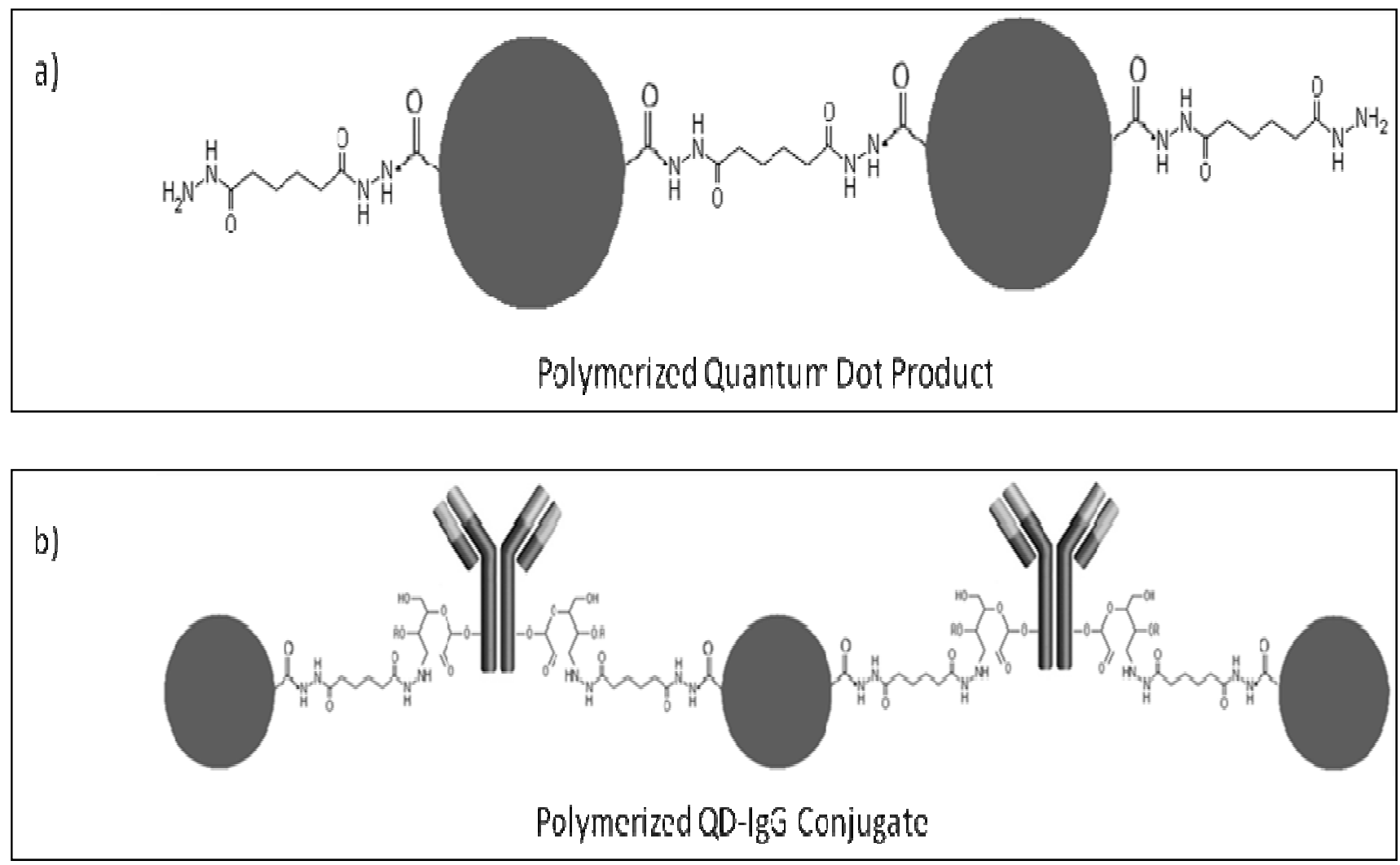

\section{Figure 8}

Possible unfavorable polymer formation during following bioconjugation steps. a) QD-hydrazide synthesis from QD-COOH, and b) QD-lgG bioconjugation from QD-hydrazide and lgG-CHO. 


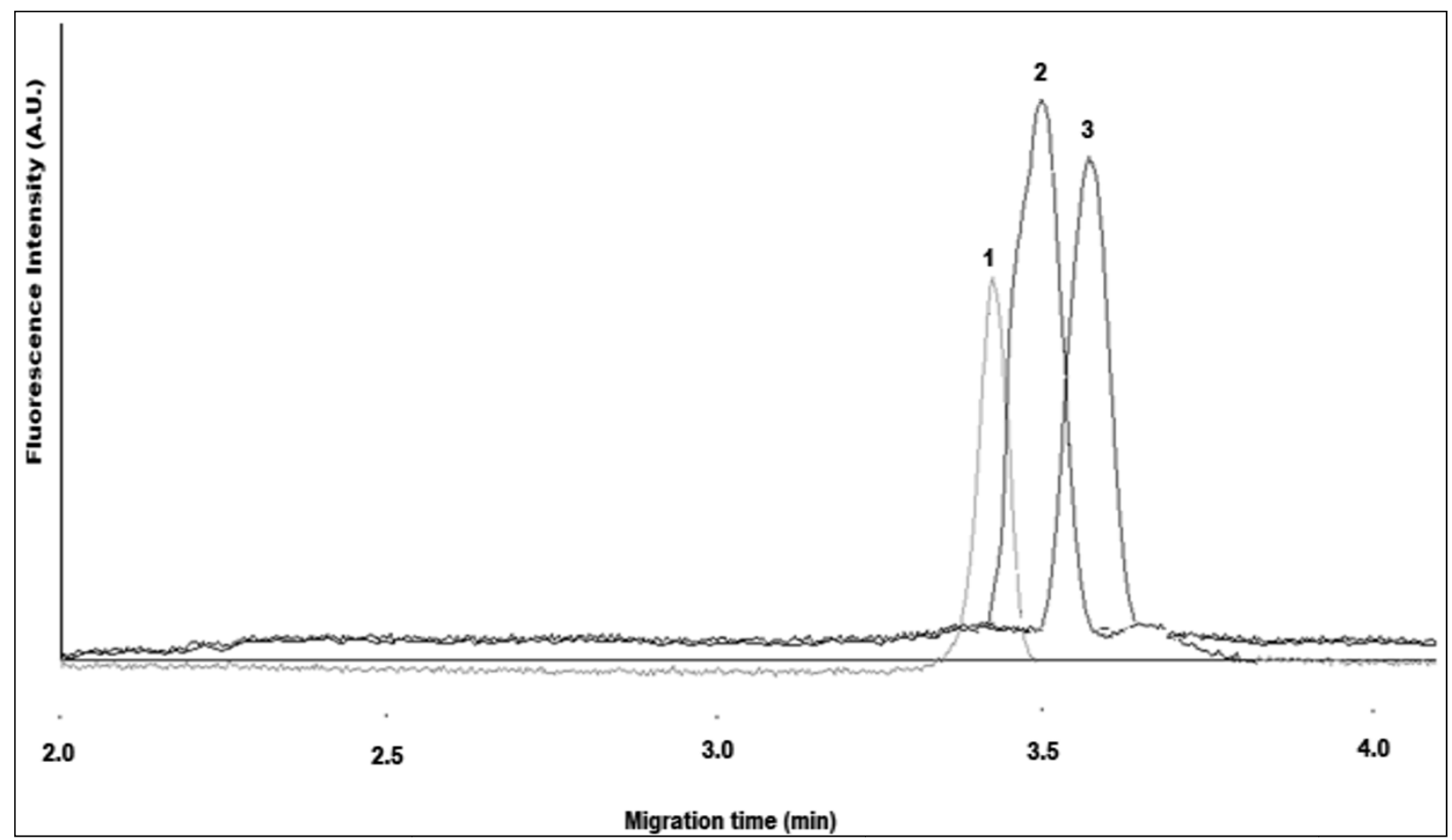

\section{Figure 9}

Overlapping electropherograms illustrating QD- $\mathrm{NH}_{2}$ (1), QD-hydrazide (2), and QD-COOH (3). CE buffer electrolyte used was $50 \mathrm{mM}$ borate, $\mathrm{pH}$ 9.2. Gravity injection performed by elevating inlet capillary $7 \mathrm{~cm}$ for $5 \mathrm{~s}$. Applied voltage for $\mathrm{CE}$ separation was $28 \mathrm{kV}$. Capillary temperature maintained at $20^{\circ} \mathrm{C}$. Excitation source and detection wavelength was $473 \mathrm{~nm}$ and $620 \mathrm{~nm}$, respectively.

pletely ionized, exhibiting a net negative charge. Figure 8 can show a distinct change in migration time between QD- $\mathrm{NH}_{2}$ and QD-COOH. Hydrazides have remarkably low pKa values ( 2.5 ), thus QD-hydrazides will be deprotonated during CE separation and exhibit a net-neutral charge. Again, this can be observed in figure 8 as QDhydrazide migrates intermediate of the positively- and negatively- charged QDs. The small differences in migration times between QDs with substantially different charged residues on their surfaces can be attributed to the very large size of the particles that greatly influence their migration. Suppression of the EOF may improve resolution by means of increased electrophoretic contributions from QD-biomolecule conjugates [33].

The use of QD-hydrazide (in contrast to QD-NH $\mathrm{H}_{2}$ ) for bioconjugation with an oxidized IgG (IgG-CHO) increases the selectivity of the reaction. However, there still remains the potential to form undesirable conjugates. The is due to not only the QD-hydrazide containing many reactive sites, but also the IgG-CHO which can contain many polysaccharide chains which can again contain many reactive aldehydes. This can lead to the uncontrolled formation of -QD-IgG-QD- polymers (Figure 8b). However, this undesirable polymer formation can possibly be minimized with using QD-hydrazide in very limited quantities with respect to the IgG-CHO during bioconjugation. Reduced reaction times, temperature, and mildly acidic $\mathrm{pH}$ conditions may also prevent undesirable conjugates.

Figure 10 illustrates the CE separation of QD-hydrazide (1) and their conjugation to whole anti-human albumin IgG-CHO (QD-IgG) (2). The separation is not baseline resolved but can be distinguished by the vertical line separating the two peaks. The QD-IgG, not purified by sizeexclusion or dialysis, retains a considerable amount of unconjugated IgG in the sample. This resulted in significant changes in EOF, peak shape, and resolution due to protein-capillary wall adsorption. In addition, the lack of baseline separation could be attributed to the whole $\operatorname{IgG}$ exerting a reduced negative charge influence when conjugated to QD-hydrazide. To reduce the effects of proteincapillary wall interaction, a $0.1 \%$ BSA additive was included in the CE separation buffer. However, due to the 


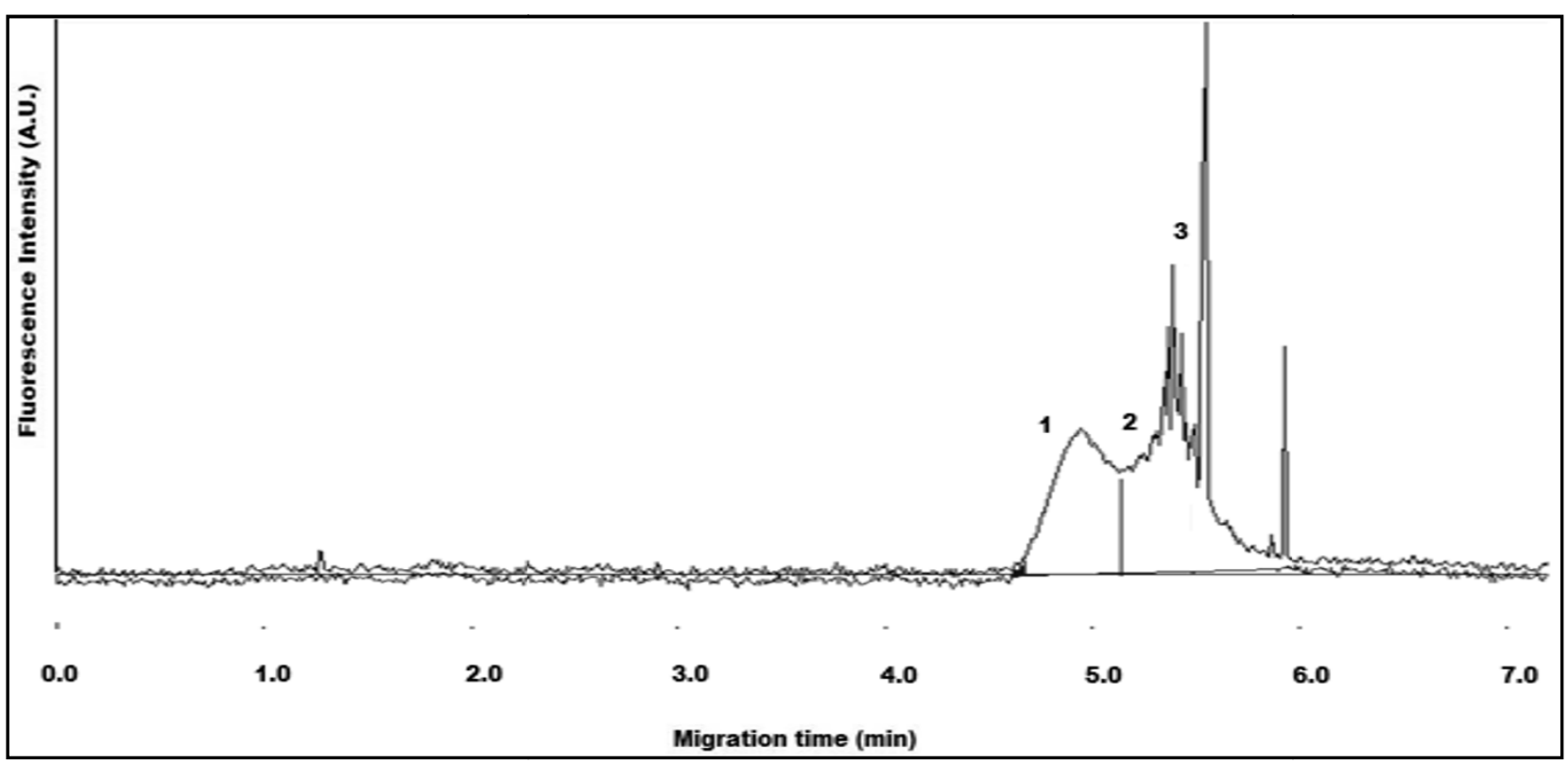

Figure 10

Non-resolved electropherogram of mixture QD-hydrazide (I) and whole antibody-conjugated QDs (QD-IgG) (2). Sharp peaks (3) observed at the migration time of QD-IgG are attributed to buffer additive (BSA) cross-reacting with the antigen-binding site of the IgG. IgG used for conjugation was rabbit anti-human albumin. CE buffer electrolyte used was $50 \mathrm{mM}$ borate ( $\mathrm{pH}$ 9.2), 0.1\% BSA. Gravity injection performed by elevating inlet capillary $7 \mathrm{~cm}$ for 5 s. Applied voltage for CE separation was $25 \mathrm{kV}$. Capillary temperature maintained at $20^{\circ} \mathrm{C}$. Excitation source and detection wavelength was $473 \mathrm{~nm}$ and 620 $\mathrm{nm}$, respectively.

similarities between BSA and the IgG immunogen, human serum albumin (HSA), cross-reactivity may have occurred. The cross-reactivity, leading to a non-specific immunoconjugate (QD-IgG-BSA) may be observed in the electropherogram as sharp spikes, unresolved from the QD-IgG peak.

\section{Characterization of immunoconjugates}

Figure 11 illustrates overlapping electropherograms of the conjugate QD-rIgG (1) in comparison when exposed to an excess of immunogen, HSA specific for the antibody (see Figure 12 for reaction scheme). There is a significant change in migration time between the bioconjugate QDrIgG and the resulting immunoconjugate QD-rIgG-HSA (2). The peak fronting observed for the QD-rIgG-HSA overlaps with QD-rIgG and could possibly be due to an incomplete immunochemical reaction. Although the reaction was allowed to take place in the presence of excess HSA, an incubation period of 15 minutes at room temperature may not have been sufficient. The difference in migration time between QD-rIgG and QD-rIgG-HSA was $\sim 25 \mathrm{~s}$. Minimal changes in migration time between successive runs were calculated ( 1.8 s) and were attributed to the excess HA present in the sample. However, these changes in migration time due to protein-capillary wall adsorption were not significant in obscuring the detection of an immunoconjugate peak.

\section{Conclusion}

In this paper we used CE-LIF to investigate the bioconjugation of QDs to proteins and immunoglobulins. The electropherograms shown above demonstrate each QDbiomolecule conjugate's electrophoretic behavior. The electropherograms for the various QD-protein, QD-rIgG, and QD-IgG conjugates displayed migration times relatively longer in contrast to QDs prior to conjugation due to increased net-negative charge influenced by the biomolecule. In addition, increased peak broadening was observed with each of the QD-biomolecule conjugates. QD polydispersity and protein/immunoglobulin properties (ie. size, pI, active functional groups for conjugation) were principal contributors for the QD-biomolecule electrophoretic behavior. Various methods for bioconjugation (selective and non-selective) were performed based on the nature of the biomolecule (ie. functional groups available). These bioconjugation techniques, while extensively used with molecular labels, can also be applied for QD labeling. However, due to QDs exhibiting fundamental differences with molecular labels, complications can arise during bioconjugation that can be detrimental to a 


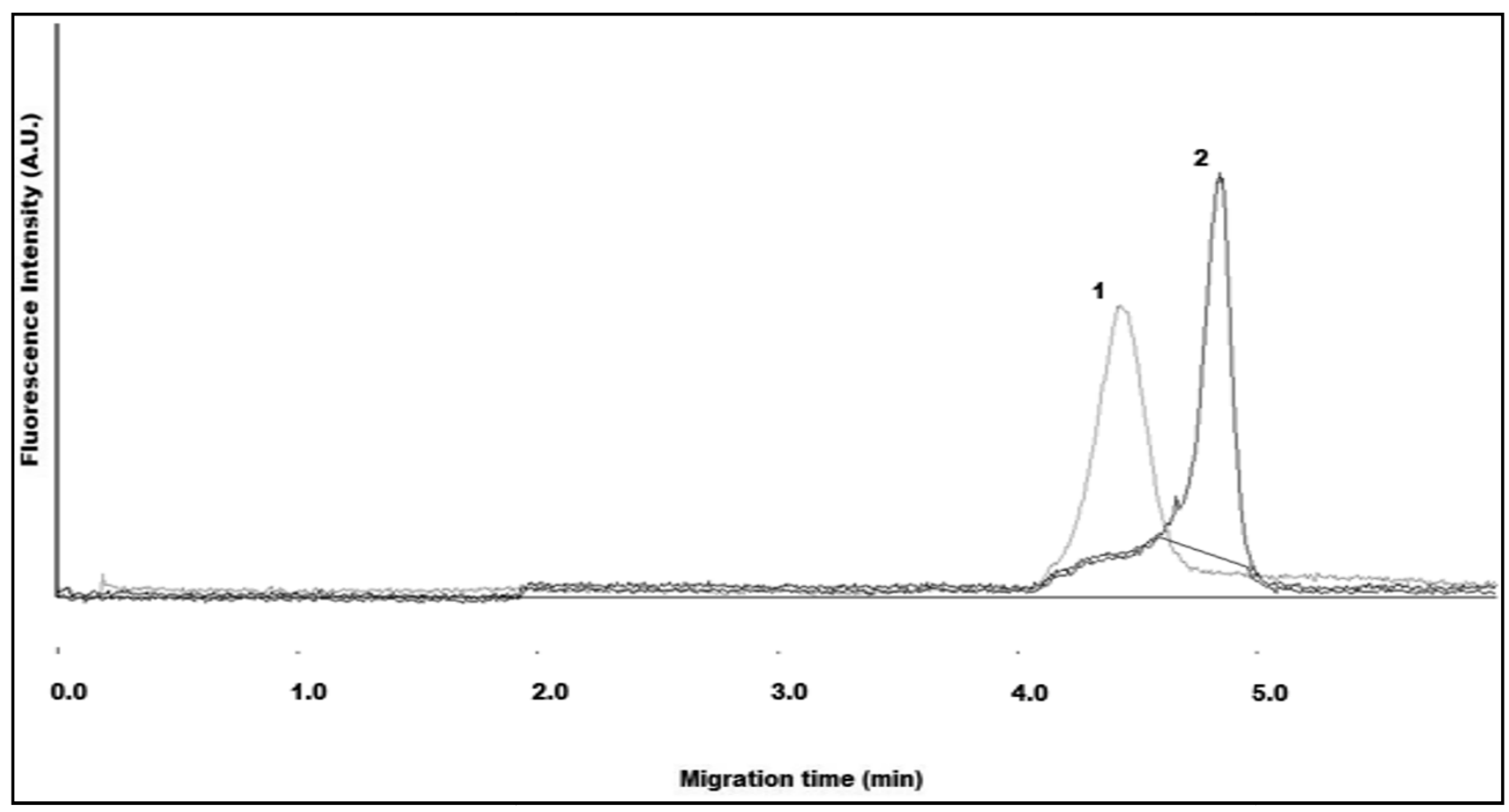

Figure II

Overlapping electropherograms illustrating QD-rlgG (I) and antibody's respected immunogen QD-rlgG-HSA (2). IgG used for conjugation was rabbit anti-human albumin. Immunogen used was human serum albumin (HSA). CE buffer electrolyte used was $50 \mathrm{mM}$ borate, $\mathrm{pH}$ 9.2. Gravity injection performed by elevating inlet capillary $7 \mathrm{~cm}$ for $5 \mathrm{~s}$. Applied voltage for CE separation was $25 \mathrm{kV}$. Capillary temperature maintained at $20^{\circ} \mathrm{C}$. Excitation source and detection wavelength was $473 \mathrm{~nm}$ and $620 \mathrm{~nm}$, respectively.

CE separation. The large size of a QD as well as its vastly functionalized surface can cause a multitude of biomolecules to conjugate with its surface. In addition, biomolecules, particularly proteins and immunoglobulins may contain many functional groups that can actively participate in the conjugation process, leading to an uncontrolled polymerization. Another underlying matter is the significant electrophoretic contribution that the QD gives

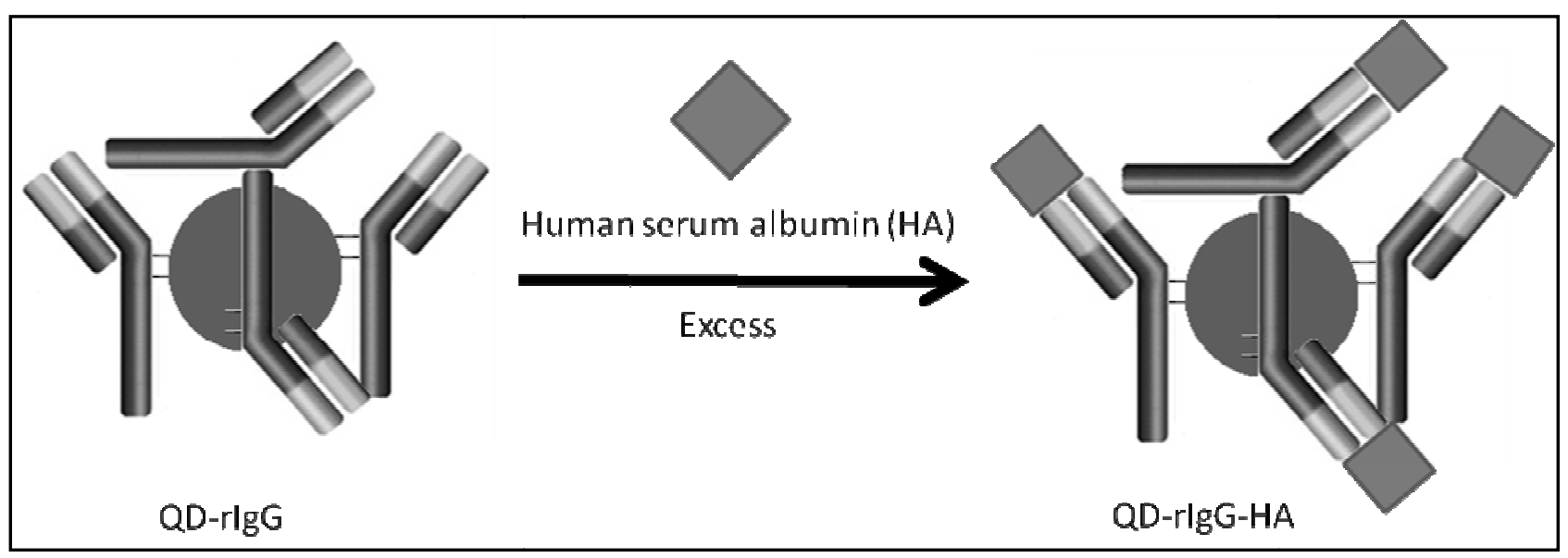

Figure 12

Immunochemical reaction between QD-rlgG and corresponding antigen human serum albumin (HSA). 
to the conjugates, due to its large size. An immunoreaction following QD-rIgG conjugation was performed with the IgG's immunogen. The resulting longer migration time for the immunoconjugate suggests a further increase in the immunoconjugate's net-negative charge, however, the peak width displayed no further broadening. Ultimately, this work will continue to evolve in an effort to perform quantum dot-based immunoassays using capillary electrophoresis as an effective and sensitive separation technique. Such work can be directed in the area of infectious biological materials that are generally present in relatively small low concentrations. This work will contribute to the advancements in applying nanotechnology for molecular diagnosis in medical field.

\section{Competing interests}

The authors declare that they have no competing interests.

\section{Authors' contributions}

MP performed all experiments and data analysis in the laboratory. Both authors designed and coordinated experiments. EPCL provided important advice and financial support. MP wrote manuscript. Both authors read and approved final manuscript.

\section{Acknowledgements}

Financial support of the Natural Sciences and Engineering Research Council (NSERC) Canada is gratefully acknowledged.

\section{References}

I. Smith AM, Nie SM: Chemical analysis and cellular imaging with quantum dots. Analyst 2004, I29:672-677.

2. Medintz IL, Uyeda HT, Goldman ER, Mattoussi H, et al.: Quantum dot bioconjugates for imaging, labelling and sensing. Nat Mater 2005, 4:435-446.

3. Parak WJ, Gerion D, Pellegrino T, Zanchet D, et al.: Biological applications of colloidal nanocrystals. Nanotechnology 2003, I 4:RI5-R27.

4. Wang SP, Mamedova N, Kotov NA, Chen W, et al:: Antigen/antibody immunocomplex from CdTe nanoparticle bioconjugates. Nano Lett 2002, 2:817-822.

5. Mamedova NN, Kotov NA, Rogach AL, Studer J, et al:: AlbuminCdTe nanoparticle bioconjugates: Preparation, structure, and interunit energy transfer with antenna effect. Nano Lett 200I, I:28I-286.

6. Lin ZB, Cui SX, Zhang $H$, Chen Q, et al.: Studies on quantum dots synthesized in aqueous solution for biological labeling via electrostatic interaction. Anal Biochem 2003, 3 I 9:239-243.

7. Huang $X Y$, Weng JF, Sang FM, Song $X$, et al.: Characterization of quantum dot bioconjugates by capillary electrophoresis with laser-induced fluorescent detection. J Chromatogr A 2006, | | | 3:25 |-254.

8. Grabarek Z, Gergely : Zero-length crosslinking procedure with the use of active esters. J Anal Biochem 1990, I 85: I 3I-I 35.

9. Xing Y, Chaudry Q, Shen C, Kong KY, Zhau HE, Chung LW, Petros JA, O'Regan RM, Yezhelyev MV, Simons JW, Wang MD, Nie S: Bioconjugated quantum dots for multiplexed and quantitative immunohistochemistry. Nature Protocols 2007, 2(5): I I 52-I I 65.

10. Hashida S, Ishikawa E: Use of normal IgG and its fragments to lower the non-specific binding of Fab'-enzyme conjugates in sandwich enzyme-immunoassay. Anal Lett 1985, I 8(B9): I |43- I I55.

II. Yoshitake S, Yamada Y, Ishikawa E, Masseyeff R: Conjugation of glucose-oxidase from aspergillus-niger and rabbit antibodies using $\mathbf{N}$-hydroxysuccinimide ester of $\mathbf{N}$-(4-carboxycyclohexylmethyl)-maleimide. Eur J Biochem 1979, I 0 I:395-9.

12. Palmer JL, Nissonoff A: Reduction and reoxidation of a critical disulfide bond in the rabbit antibody molecule. J Biol Chem 1963, 238:2393.

13. Radko SP, Chrambach A: Separation and characterization of sub-mu $\mathbf{m}$ - and $\mathbf{m u} \mathbf{m}$-sized particles by capillary zone electrophoresis. Electrophoresis 2002, 23:1957-1972.

14. Quang C, Petersen SL, Ducatte GR, Ballou NE, et al.: Characterization and separation of inorganic fine particles by capillary electrophoresis with an indifferent electrolyte system. J Chromatogr A 1996, 732:377-384.

15. Vanifatova NG, Spivakov BY, Mattusch J, Spivakov BYa, Vanifatova NG: Investigation of iron oxide nanoparticles by capillary zone electrophoresis. Talanta 2005, 66:605-6I0.

16. Liu FK, Ko FH, Huang PW, Wu CH, Chu TC: Studying the size/ shape separation and optical properties of silver nanoparticles by capillary electrophoresis. J Chromatogr A 2005, 1062:139-145.

17. Liu FK, Lin YY, Wu CH: Highly efficient approach for characterizing nanometer-sized gold particles by capillary electrophoresis. Anal Chim Acta 2005, 528:249-254.

18. Jones HK, Ballou NE: Separations of chemically different particles by capillary electrophoresis. Anal Chem 1990, 62:2484-2490.

19. Cifuentes A, Rodriguez MA, García-Montelongo FJ: Separation of basic proteins in free solution capillary electrophoresis: Effect of additive, temperature and voltage. J Chromatogr A 1996, 742:257-266.

20. Chen FTA: Rapid protein-analysis by capillary electrophoresis. J Chromatogr 199I, 559:445-453.

21. Dolník V: Applications of capillary electrophoresis on microchip. Electrophoresis 2006, 28(I 5): 1094-2009.

22. Baryla NE, Lucy CA: Simultaneous separation of cationic and anionic proteins using zwitterionic surfactants in capillary electrophoresis. Anal Chem 2000, 72:2280-2284.

23. Wei W, Ju HX: Application of dodecyldimethyl (2-hydroxy-3sulfopropyl) ammonium in wall modification for capillary electrophoresis separation of proteins. Electrophoresis 2005, 26:586-592.

24. Schmerr MJ, Goodwin KR, Cutlip RC: Capillary electrophorsis of the scrapie prion protein from sheep brain. J Chromatogr $A$ 1994, 680:447-453.

25. Schmerr MJ, Goodwin KR, Cutlip RC, Jenny AL: Improvements in a competition assay to detect scrapie prion protein by capillary electrophoresis. J Chromatogr B 1996, 68 I:29-35.

26. Schmerr MJ, Jenny A: A diagnostic test for scrapie-infected sheep using a capillary electrophoresis immunoassay with fluorescent-labeled peptides. Electrophoresis 1998, 19:409-4|4.

27. Schmerr MJ, Jenny AL, Bulgin MS, Miller JM, et al.: Use of capillary electrophoresis and fluorescent labeled peptides to detect the abnormal prion protein in the blood of animals that are infected with a transmissible spongiform encephalopathy. J Chromatogr A 1999, 853:207-214.

28. Jackman R, Schmerr MJ: Analysis of the performance of antibody capture methods using fluorescent peptides with capillary zone electrophoresis with laser-induced fluorescence. Electrophoresis 2003, 24:892-896.

29. Yang WC, Schmerr MJ, Jackman R, Bodemer W, Yeung ES: Capillary electrophoresis-based noncompetitive immunoassay for the prion protein using fluorescein-labeled protein a as a fluorescent probe. Anal Chem 2005, 77:4489-4494.

30. Yang WC, Yeung ES, Schmerr MJ: Detection of prion protein using a capillary electrophoresis-based competitive immunoassay with laser-induced fluorescence detection and cyclodextrin-aided separation. Electrophoresis 2005, 26:1751-1759.

31. Song X, Li L, Qian H, Fang N, Ren J: Highly efficient size separation of $\mathrm{CdTe}$ quantum dots by capillary gel electrophoresis using polymer solution as sieving medium. Electrophoresis 2006, 27: $|34|-1346$.

32. Weng J, Song X, Li L, Qian H, Chen K, Xu X, Cao C, Ren J: Highly luminescent CdTe quantum dots prepared in aqueous phase as an alternative fluorescent probe for cell imaging. Talanta 2006, 70:397-402.

33. Feng HT, Law WS, Yu LJ, Li SFY: Immunoassay by capillary electrophoresis with quantum dots. Chromatogr A 2007, I I 56:75-79. 
34. Vicente G, Colon LA: Separation of bioconjugated quantum dots using capillary electrophoresis. Anal Chem 2008, 80:1988-1994.

35. Pereira M, Lai EPC, Hollebone B: Characterization of quantum dots using capillary zone electrophoresis. Electrophoresis 2007, 28:2874-288I.

Publish with Biomed Central and every scientist can read your work free of charge

"BioMed Central will be the most significant development for disseminating the results of biomedical research in our lifetime. " Sir Paul Nurse, Cancer Research UK

Your research papers will be:

- available free of charge to the entire biomedical community

- peer reviewed and published immediately upon acceptance

- cited in PubMed and archived on PubMed Central

- yours - you keep the copyright 